\title{
Sciendo
}

Wroclaw $\underline{\text { Review }}$

of Law, Administration \& Economics

\section{ENVIRONMENTAl COMPliance CONTROL}

\author{
MALGOSIA FITZMAURICE*
}

\section{INTRODUCTION}

International environmental law, and its enforcement, was one of the areas of interest of Professor Wolfke. In 1979, he published a seminal monograph "International Environmental Law: Creation and Enforcement". It is a visionary book, in which Professor Wolfke noted that international environmental law is part of international law and that the law governing environmental protection is multilayered and complex. Certain aspects of international environmental law have remained the same as they were at the time of Professor Wolfke's monograph. It is mostly regulated by treaties and customary international law plays a secondary role. Professor Wolfke also observed that the decisions of international organisations influence the formation of international environmental law. One of the considerations in his seminal book was the question of the enforcement of international environmental law. Professor Wolfke, in a truly visionary manner, mentioned actio popularis as one of the means of its enforcement, which, in 1979, was a very progressive statement. Only in 2014 in the Whaling in Antartic case ${ }^{1}$, has his prophecy become the reality.

\section{GENERAL COMMENTS ON COMPLIANCE WITHIN INTERNATIONAL ENVIRONMENTAL LAW}

As in general international law compliance, it is linked with several theoretical problems, such as the role of countermeasures; State responsibility, and compliance with binding and non-binding legal instruments. Overall, the concept of environmental compliance control may be said to involve not just the development of new legal principles, but also a new attitude within the international community, as well as among governments and civil society at the national level, towards the governance of the global response to environmental challenges.

DOI: $10.1515 /$ wrlae-2018-0054

*Professor of Public International Law, Queen Mary University of London, m.fitzmaurice@qmul.ac.uk.

${ }^{1}$ Whaling in Antartic (Australia v Japan, New Zealand intervening), http://www.icjcij.org/docket/files/148/18136.pdf. 


\section{Theories of compliance control}

There are many theories which are aimed at an explanation of compliance. Chayes and Handler Chayes, in their book The New Sovereignty, present a model which is based on a "so-called" managerial approach, which is process-oriented. They are of the view that legal norms alone are not sufficient to evoke compliance, but rather, must form the part of the nexus of interactions between parties and play an important role within interactions aimed at promoting compliance. The adherence to legal norms is not a result of a coercive action, but is linked to the legitimacy of the norms that is the result of a correct process. Chayes and Handler Chayes present the view that the lack of compliance is not willful but rather a result of other factors such as, e.g. the lack of relevant information or the lack of capacity. Managerial strategy is 'verbal, interactive, and consensual'. Chayes and Handler Chayes ${ }^{2}$ express views similar to institutionalists (Keohane and Nye) who base compliance on the interdependence of a diversified nature between States resulting in institutional co-operation, enhancing compliance through various methods; such as reporting, monitoring, and verification. ${ }^{3}$

The theory of compliance by $\mathrm{Koh}^{4}$ is based on close vertical interactions between various actors, both private and public, through discursive interpretations of international norms, mainly by domestic institutions, as the key policy-makers. Brunnée and Toope represent a socalled 'interactional theory' which is also based on interactions by States, which rests on 'stable patterns of expectations'. 5 Transformationalists (Downs, Rocke, and Barstoon) are of the view that compliance appears to be high in regimes requiring slightly more from States than they are expected to do in the absence of a regime. For regimes which are based on 'deep cooperation', eliciting compliance from States is highly problematical and, according to these authors, non-compliance is willful. ${ }^{6}$

\section{The role of countermeasures in compliance}

This is one of the decisive issues in theories regarding compliance control. Chayes and Handler Chayes are strong opponents of the imposition of countermeasures in order to elicit compliance. They have identified several reasons why countermeasures are not a practical option in compliance control. First of all, they argue that the critical precondition of countermeasures in the domestic legal system is that a State has a monopoly - or a near monopoly-of force. This is not the case at the international level. Chayes ([1997] at 54) submits that '[s]anctions are costly; they lack legitimacy; they are leaky'. Chayes and Handler Chayes mention

\footnotetext{
2 A Chayes 'Compliance without Enforcement' (1997) 91 ASIL Proceedings 53-57; A Chayes, A Handler Chayes 'On Compliance' (1993) 47 IntlOrg 175-205; A Chayes and A Handler Chayes, The New Sovereignty: Compliance with International Regulatory Agreements (1998).

${ }^{3}$ RO Keohane and JS Nye, Power and Interdependence: World Politics in Transition (1977); R Keohane and J Nye 'Power and Interdependence Revisited' (1987) 41 IntlOrg 725-53.

${ }^{4}$ HH Koh 'Why Do Nations Obey International Law' (1997) 106 YaleLJ 2599-659.

5 J Brunnée and SJ Toope 'Environmental Security and Freshwater Resources: Ecosystem Regime Building' (1997) 91 AJIL 26-59.

${ }^{6} \mathrm{GW}$ Downs DM Rocke, and PN Barsoom 'Is the Good News about Compliance Good News about Cooperation?' (1996) 50 IntlOrg 379-406.
} 
divergent political interests and that the burden of countermeasures falls on those least able to bear it. Thus, they have suggested an alternative, i.e. a managerial approach, which is based on a premise of in-depth co-operation between States. Brunnée and Toope express a similar view that countermeasures - and an adjudicative dispute settlement mechanism-are too coercive, adversarial, and backward-looking. Downs, Rocke, and Barstoon express views that are fundamentally different from those of Chayes and Handler Chayes as they are proponents of countermeasures. They argue that the absence of enforcement threats may not be caused by the irrelevance of enforcement but, rather, by the tendency of States to avoid deep cooperation; a tendency linked to the enforcement costs necessary to eliminate cheating. Jacobson and Brown Weiss adhere to yet a different approach. ${ }^{7}$ According to these authors there is a nexus of factors which influence the compliance of States, such as the character of the problem, the characteristics of the treaty, and, most importantly, national factors, which include, inter alia, economic status, administrative capacity, and the links between national, provincial, and local governments. These authors argue that, according to empirical research, if countries are to comply, engaging them in the agreement is of fundamental importance. Jacobson and Brown Weiss distinguish three alternative compliance strategies: sunshine; incentives; and sanctions. The selection of strategies depends upon individual States' intent and capacity, as well as upon the type of international agreement, e.g. trade, labour, human rights, the environment.

\section{ISSUES CONCERNING THE DEFINITION OF COMPLIANCE AND ENFORCEMENT}

\section{Definition}

There is as yet no uniformly accepted, authoritative definition of compliance in international environmental treaties, or in the practice of international organizations. MEAs frequently use the terms 'implementation', 'compliance', and 'non-compliance'; but these terms are rarely defined in their texts. The most fundamental documents of international environmental law, i.e. the Stockholm Declaration (1972) and Rio Declaration (1992), Agenda 21 and the 2002 Johannesburg Declaration on Sustainable Development and Plan of Implementation (Sustainable Development), do not contain any workable definitions of implementation, compliance or enforcement. In Agenda 21, the whole of Sec. IV on 'Means of Implementation' is 'about' compliance control. But if one turns to Chapter 39 on International Legal Instruments and Mechanisms for some kind of legal definition, the best that can be found, contained in Chapter $39 \mathrm{~B}$ is a provision

\footnotetext{
${ }^{7}$ E Brown Weiss and HK Jacobson 'A Framework for Analysis' in E Brown Weiss and HK Jacobson (eds) Engaging Countries: Strengthening Compliance with International Environmental Accords (1998).
} 
(39.8) according to which the parties to international agreements are enjoined to 'consider procedures and mechanisms to promote and review their effective, full and prompt implementation', by 'inter alia', establishing efficient and practical reporting systems, or considering ways in which relevant international bodies, such as the United Nations Environment Programme (UNEP), might contribute towards the further development of 'such mechanisms'. Due to the lack of a legal definition of the terms compliance, implementation, and enforcement, several publicists provided their own definitions of these terms. Wolfrum defined compliance as meaning 'that commitments entered into by States are fully effectuated in practice', which therefore imposes on States an obligation to undertake positive specific actions at both international and national levels. ${ }^{8}$ Examples of the following definitions can be given: 'Implementation of international norms refers to incorporating them in domestic law through legislation, judicial decision, executive decree, or other process'. 'Compliance includes implementation, but is broader, concerned with factual matching of State behaviour and international norms: "compliance refers to whether countries in fact adhere to the provisions of the accord and the implementing measures they instituted"" 9 Brown Weiss and Jacobson note that compliance has several dimensions. Treaties contain specific obligations that can be procedural (e.g. reporting) and substantive (to cease or control activity). Procedural obligations are aimed at complying with the substantive ones. However, compliance with the procedural obligations does not ensure compliance with substantive ones and vice versa. ${ }^{10}$

In traditional legal theory, this concept is embodied in the principle pacta sunt servanda; Art. 26 Vienna Convention on the Law of Treaties (1969) which imposes on States the duty of the effective implementation. This involves not only taking actions in fulfillment of treaty obligations at the international level, but also translates into an obligation to adopt legislative and administrative measures under national laws to secure the application of a treaty (e.g. the 1982 United Nations Convention on the Law of the Sea). But compliance control calls for a wider and more complex definition, as it obliges States not only to adopt laws and regulations pursuant to treaty obligations, but as well to provide the necessary administrative procedures for the enforcement of the respective rules on the national level. Enforcement is defined by Wolfrum as all the actions adopted by States, as well as nonState entities, to incite or compel a State to achieve compliance with its international obligations. ${ }^{11}$ Therefore international procedures which are set up to deal with non-compliance should comprise the following elements: preventing non-compliance by co-operation; the possibility of compliance

\footnotetext{
${ }^{8} \mathrm{R}$ Wolfrum 'Means of Ensuring Compliance with and Enforcement of International Environmental Law' (1998) 272 RdC 9.

${ }^{9}$ Shelton (ed) Commitment and Compliance: The Role of Non-Binding Norms in the International Legal System (2000) 535-53, 'Introduction' 5, citing Brown Weiss and Jacobson.

${ }^{10}$ E Brown Weiss and HK Jacobson 'A Framework for Analysis' in E Brown Weiss and HK Jacobson (eds) Engaging Countries: Strengthening Compliance with International Environmental Accords (1998).

${ }^{11} \mathrm{R}$ Wolfrum 'Means of Ensuring Compliance with and Enforcement of International Environmental Law' (1998) 272 RdC 9-154.
} 
assessment; assistance in cases of non-compliance; settling of disputes; and enforcement. It is therefore a very complicated nexus of various elements forming one system.

\section{Definitions from the UNEP Guidelines}

The 2002 UNEP Guidelines on Compliance with and Enforcement of Multilateral Environmental Agreements ('UNEP Guidelines'), ${ }^{12}$ in Part I on Enhancing Compliance with Multilateral Environmental Agreements defines compliance as 'the fulfillment by the contracting parties of their obligations under a multilateral environmental agreement and any amendments to the multilateral environmental agreement'. Implementation refers to, inter alia, all relevant rules and regulations, policies, and other measures and initiatives that contracting parties adopt and/or take to meet their obligations under a multilateral agreement and its amendments, if any. However, Part II of the Guidelines on National Enforcement includes a different set of definitions, as it is argued that the term compliance has different relevance within the respective areas covered by both chapters and, in so far as it relates to both these areas, it has different connotations. For the purpose of the Guidelines, the following definitions have been provided:

'Compliance' means the state of conformity with obligations, imposed by a State, its competent authorities and agencies on the regional community, whether directly or through conditions and requirements in permits, licences and authorisations, in implementing multilateral environmental agreements. (Art. 38 (a))

'Environmental law violation' means that contravention of national environmental laws and regulations implementing multilateral environmental agreements. (Art. 38 (b))

'enforcement' means the range of procedure and actions employed by a State, its competent authorities and agencies to ensure that organisations or persons, potentially failing to comply with environmental laws and regulations implementing multilateral environmental agreements, can be brought or returned into compliance and /or punished through civil, administrative or criminal action. The second set of definitions relates to national, not international, enforcement. (Art. 38 (d)).

\section{TeChNiques OF COMPLIANCE CONTROL}

Facilitating and compelling compliance under MEAs may be promoted by non-confrontational and confrontational means. There is no single definition of confrontational and non-confrontational measures aimed at facilitating and compelling compliance. The UNEP Study on Dispute Avoidance and Dispute Settlement in International Environmental Law ${ }^{13}$ stressed the need for the recourse to less confrontational approaches within the system of dispute settlement, such as good offices, meditation, and conciliation, which were recommended as first options. Wolfrum defines

\footnotetext{
${ }^{12} \mathrm{http} / / / \mathrm{www}$. unep.org/delc/Portals/119/UNEP.Guidelines.on.Compliance.MEA.pdf .

${ }^{13}$ UN Doc UNEP/GC.20/INF/16.
} 
confrontational and non-confrontational measures within the broader category of measures available under international law, not limited to certain means within the system of dispute settlement procedures. According to this author, the group of confrontational measures may contain the withdrawing of privileges in a particular regime; trade restrictions, the invocation of liability for environmental damage or damage resulting therefrom or the invocation of dispute settlement (at 56). The same author states that instead of recourse to confrontational measures to ensure compliance with standards or obligations, recent MEAs 'have developed procedures which assist States to live up to their obligations' (at 101). Such procedures are not meant to replace the procedures which are designed to enforce international obligations, but to supplement them. There are still certain aspects of both procedures which are not fully explored, such as whether confrontational means can be invoked before non-confrontational ones have been exhausted. Wolfrum is of the view that in situations in which non-compliance is a result of economic or technological incapability or setting of different priorities, applying enforcement measures generally will not be successful. In situations like this, compliance may be achieved by balancing environmental commitments 'by potential economic benefits which make adherence to the respective treaty and compliance therewith in general more acceptable' or 'by assisting individual States in particular cases in the compliance with obligations entered into' (at 110).

\section{Facilitative Compliance TeChNiQueS}

The UNEP Guidelines include several compliance-enhancing measures: such as clarity of the obligations of the States Parties; national implementation plans could be required in MEAs, which could potentially include environmental effects monitoring and evaluation in order to determine whether an MEA results in environmental improvement; reporting, monitoring and verification of information obtained on compliance. The Guidelines acknowledged that compliance mechanisms and procedures should take account of the particular characteristics of the agreement in question. These Guidelines are intended to facilitate considerations of compliance issues already at the design and negotiations stages, as well as after the entry into force of MEAs, at conferences and meetings of the parties. The Guidelines encourage effective approaches to compliance, outline strategies and measures to strengthen implementation of MEAs, through relevant laws and regulations, policies, and other measures at the national level and guide sub-regional, regional, and international co-operation in this regard.

\section{Monitoring, reporting, and verification processes}

As noted by UNEP, reporting, monitoring, and verification, which are very closely linked, constitute part and parcel of the facilitative compliance process. Therefore clear distinctions are difficult to discern and maintain and somewhat artificial. The UNEP Guidelines say that MEAs can, but are not obliged to, include provisions for reporting, monitoring, and verification. The 
UNEP Guidelines describe reporting, monitoring, and verification in the following manner (Art. 14 (c) (i)-(iii)):

a) Reporting: involves regular and timely reporting by parties to MEAs on compliance generally and on specific obligations, and on non-compliance, on the basis of a common format. Secretariats to MEAs can consolidate responses received to assist in the assessment of compliance.

b) Monitoring: involves the collection of data and in accordance with the provisions of an MEA which can be used to assess compliance with it, identify problems and to suggest solutions.

c) Verification may involve verification of data and technical information (mainly sourced from national reporting systems) in order to assist in ascertaining whether a party is in compliance and, in the event of non-compliance, the degree, type, and frequency of noncompliance.

Monitoring may encompass various forms, such as reporting, on-site field visits, regular conferences at which States report. There is no rule, as to what bodies collect data. It may be secretariats of the MEA, or special bodies, sometimes assisted by non-governmental organizations ('NGOs').

The practice, in regards to reporting pursuant to international agreements, suffered, to a certain extent, the effects of poorly executed national reports from then communist States due to uncertainty of scientific data and the general lack of transparency.

The 1990s witnessed the development of a more accomplished system of reporting established under the 1992 United Nations Framework Convention on Climate Change ('Climate Change Framework Convention'), which introduced a verification system with a notable independent review element. The first Conference of the parties adopted a decision that national reports should be submitted to an in-depth review by expert review teams. Experts were nominated by the parties and selected by the Secretariat established under the Convention. The membership of these teams reflects the balance between both Annex I and non-Annex I Parties and a variety of expertise. An efficient verification process appears to be an indispensable element of global emissions trading. The current phase of development in monitoring, reporting, and verification is reflected by the role of the bodies specially set up for this purpose within non-compliance mechanisms - such as the Implementation Committee of the Montreal Protocol on Substances that Deplete the Ozone Layer. However, such in-depth reporting, including the input of third parties to a verification process, does not feature in other conventions.

In general, reporting is a very common feature of MEAs and it serves as a fundamental means for data-gathering about the level of national implementation. Information is provided mainly by way of self-reporting by States Parties to an MEA. The most important feature of reporting is that it obliges parties to MEAs to appraise, in a transparent manner, the measures adopted by parties to implement their commitments and consider the effectiveness of those measures. It is of great assistance to the parties, conferences of the parties ('COPs'), secretariat, and other organs to observe potential trends in compliance and enforcement, identify innovative 
approaches that might serve as models for other States, and allocate resources to improve compliance and enforcement (e.g. UNEP Manual on Compliance with and Enforcement of Multilateral Environmental Agreements).

The format and the frequency of such reporting vary in MEAs from annual reports (such as the Montreal Protocol on Substances that Deplete Ozone Layer) to annual and biennial reports (such as in the Convention on International Trade in Endangered Species of Wild Fauna and Flora ['CITES']) to triennial reports (such as the 1989 Convention on the Conservation of Migratory Species ('Bonn Convention']). CITES has a very sophisticated reporting system. It provides for different types of reporting regarding trade in endangered species, depending on whether an item appears in Appendices I, II, or III. For Appendix I detailed information on both import and export of species is required. Information had been collated by the UNEP World Conservation Monitoring Centre which prepares reports to CITES. CITES also provides for on-site, ad hoc verification missions conducted by the Secretariat to the Parties experiencing problems in implementation of the Convention. In principle, they can be conducted with the agreement of the party. The Meeting of the Parties to CITES every two years has a very important function of constituting a forum for States to report violations of CITES. National reports are publicly available. One more important development should be mentioned, namely the developing use of information technology, including with photographs, in order to communicate between customs officers at the border and the central office responsible for the country's enforcement. Not all MEAs include explicit monitoring and verification provisions. For example the 1989 Convention on Transboundary Movement of Hazardous Wastes ('Basel Convention') (Hazardous Wastes, Transboundary Impacts) provides for a 'verification procedure' (Art. 19), on the other hand, the 1994 Convention to Combat Desertification does not include such a provision. In many MEAs that have very brief provisions on monitoring and verification procedures, such processes were nevertheless developed on the basis of a decision by the COPs. Such an example is the 1992 Convention on Biological Diversity._ On the basis of the tightly drafted Art. 7, detailed compliance procedures were developed by subsequent decisions of the $\mathrm{COP}^{14}$. In some MEAs, such as CITES, such procedures were already included in the text of the Convention.

\section{Capacity building, financial mechanisms, technology transfer}

Compliance with MEAs may be promoted by incentives which may include facilitation, capacity building, access to special funds or the marketbased. Art. 33 UNEP Guidelines states that the building and strengthening of capacities may be necessary for developing countries that are parties to MEAs (including the least developed countries and countries with economies in transition). To this end the following means are listed: capacity building and technology transfer; financial and technical assistance; participation of a wide range of stakeholders can be promoted; various funding sources can be mobilized to finance capacity-building activities in order to enhance

\footnotetext{
${ }^{14}$ See COP 3 Decision III/10 'Identification, Monitoring and Assessment and COP 8 Decision VIII/15 'Framework for Monitoring Implementation of the Achievement of the 2010 Target and Integration of Targets into the Thematic Programmes of Work').
} 
compliance with MEAs — including the Global Environment Facility (GEF); multilateral development banks; special funds attached to MEAs; private funding, etc. Capacity building and technology transfer are important means, the lack of which will mean that developing countries and transitional economies will not benefit from the environmental, social, and economic benefits resulting from full compliance with MEAs (UNEP Guidelines). The Rio Declaration, Agenda 21, and the 2002 World Summit on Sustainable Development Plan of Implementation call for capacity-building. More specifically, many MEAs expressly provide for capacity-building and technology transfer efforts to improve compliance, taking into account the special situations of developing countries, and countries with economies in transition, including small island developing States ('SIDS'). Examples include the Convention on Biological Diversity (Art. 12), the United Nations Convention to Combat Desertification (Art. 19), and the Montreal Protocol on Substances that Deplete the Ozone Layer (Art. 10A and B). The Convention on Biological Diversity has a number of relevant provisions: Art. 12 (research and training), Art. 16 (access to and transfer of technology), and Art. 19 (handling of biotechnology and distribution of its benefits). Capacitybuilding assistance has been made available by a number of major international organizations such as the UNEP, the United Nations Development Programme (UNDP), the World Bank (World Bank Group), the Food and Agriculture Organization of the United Nations (FAO), and the United Nations Children's Fund (UNICEF). The launch of Type II partnerships at the World Summit on Sustainable Development in 2002 is a current example of capacity-building. These partnerships are based on cooperation by international organizations, NGOs, developed and developing countries, in order to identify the specific needs of developing countries regarding particular environmental problems and to develop programmes and initiatives to address these problems. Financial mechanisms aimed at facilitating compliance arise in several ways. First, financial mechanisms and/or special funds are set up under the provisions of most MEAs and may involve the financing of general capacity-building activities in developing countries and countries with economies in transition or of specific projects aimed directly at enabling such countries to meet their specific obligations under the relevant agreements. An example is the Multilateral Fund set up under the 1987 Montreal Protocol). Further examples are the three funding mechanisms established under the 1971 Convention on Wetlands of International Importance Especially as Waterfowl Habitat ('Ramsar Convention'): (i) a Small Grants Fund for Wetland Conservation and Wise Use (a global program), (ii) Wetlands for the Future (a program for Latin America and the Caribbean), and (iii) the Swiss Grant Fund for Africa. In addition, private sources, bilateral donors, and NGOs frequently provide financial resources to protect and manage wetlands. A financial mechanism has also been established under the United Nations Framework Convention on Climate Change, which is operated by the GEF and involves the setting up of a number of special funds, e.g. the Climate Change Fund and the Fund for least developed countries ('LDCs'). Furthermore, the Convention on Biological Diversity requires developed countries, again using the GEF, to assist in enabling developing countries to cover the incremental costs of 
meeting their obligations. However, there are some MEAs of fundamental importance which have very limited financial funds and lack of access to the GEF, such as the CITES. In such an instance, the main methods of facilitating compliance are through the means of the organizing workshops, providing advice and technical assistance, and secretariat missions. Funding for certain projects is provided by the GEF, which is an independent financial organization, in order to assist developing countries. The GEF grants support projects related generally to biodiversity, climate change, international waters (International Watercourses, Environmental Protection), land degradation, the ozone layer (Ozone Layer, International Protection), and persistent organic pollutants, as well as fulfilling specific funding requirements under mandates from particular MEAs. Additionally, the United Nations Agencies, such as the World Bank or UNDP set up mechanisms or projects which have the objective of assisting in achieving the objectives of MEAs without necessarily being linked to the specific obligations of parties under them. For instance, there are innovative market-based incentives, such as those applied in relation to the protection of the ozone layer by the World Bank, or, for example, by increasing the cost effectiveness of phase out projects. Finally, an important addition to facilitative measures, this time aimed specifically at assisting developed countries in meeting their obligations, was provided in the 1997 Kyoto Protocol in the form of 'flexible mechanisms': clean development mechanism; joint implementation; and emissions trading.

\section{REACTION TO NON-COMPLIANCE UNDER GENERAL INTERNATIONAL LAW}

Apart from the techniques of compliance control referred to above, which may be seen as being innovative, and often going beyond the strictly legal field, traditional international law provides certain means which, in part, have the objective of encouraging and/or enforcing compliance with legal obligations.

\section{Art. 60 Vienna Convention of the $\mathbf{1 9 6 9}$ Vienna Convention on Law of Treaties}

Under Art. 60 VCLT a material breach of a multilateral treaty by one of the parties entitles the other parties to suspend the operation of a treaty in whole or in part or to terminate it either in relation to themselves or the defaulting State or between all the parties. It is now generally accepted that this procedure constitutes an inappropriate response to a party's breach of the provisions of an international environmental agreement. In such circumstances the fundamental objectives of the convention as well as the interests of the 'innocent' parties lie in bringing the defaulting State back into compliance rather than to suspend or terminate a treaty.

\section{Countermeasures}

Under the law of State responsibility an injured State may take countermeasures against a State which is responsible for an internationally wrongful act in order to induce that State to comply with its obligations. Arts. 
42 and 48 ILC Draft on State Responsibility define a State Party entitled to invoke material breach. Art. 48 provides for the invocation of State responsibility by a State other than the injured State, and in para. 1 (a), provides for the possibility of the invocation of State responsibility for the protection of a collective interest which may derive from a multilateral treaty or from customary international-so-called obligations erga omnes partes. Examples of treaties under which such a procedure might arise include the Montreal Protocol and the Kyoto Protocol. The example of the implementation of the obligation erga omnes partes in the Whaling in Antarctic case in which both Australia and New Zealand were not directly harmed States. To the extent that countermeasures are intended to be temporary and to induce a defaulting State quickly to return to a state of compliance, they may be seen as more suitable to the requirements of conventions aimed at environmental protection.

\section{Settlement of Dispute Procedure}

The UNEP Guidelines consider the settlement of disputes as a means to complement the provisions aimed at compliance (para. 17). The means of the settlement of disputes in MEAs reflect those enumerated in Art. 33 United Nations Charter. For example, the 1985 Vienna Convention on the Protection of the Ozone Layer sets out the following procedure: in the event of a dispute between parties concerning the interpretation or application of the Convention, the parties are obliged to first seek a solution by negotiation. If this fails, the next step is to jointly seek the good offices of, or request mediation by, a third party. The parties may make a special declaration of acceptance concerning one or both of the following means of dispute settlement as compulsory: $a$ ) arbitration in accordance with procedures to be adopted by the Conference of the Parties at its first ordinary meeting; $b$ ) submission of the dispute to the International Court of Justice (ICJ). If the parties have not, in accordance with the procedures described above, accepted the same or any procedure, the dispute shall be submitted to conciliation, unless the parties otherwise agree. The commission renders a final and recommendatory award, which the parties shall consider in good faith (bona fide). According to Art. XVIII CITES, any dispute which may arise between two or more parties with respect to the interpretation or application of the provisions of that Convention, must be handled through negotiation between the parties involved in the dispute. If the dispute cannot be resolved through negotiation, the parties may, by mutual consent, submit the dispute to arbitration, in particular that of the Permanent Court of Arbitration (PCA) at The Hague, and the parties submitting the dispute shall be bound by the arbitral decision. The 1991 Convention on Environmental Impact Assessment in a Transboundary Context ('Espoo Convention') has very elaborate dispute settlement procedures. Apart from the classic settlement of dispute mechanisms contained in Art. 15 Espoo Convention, which follows the pattern of e.g. the 1985 Vienna Convention on the Protection of the Ozone Layer, it provides that, in case of a dispute concerning the likelihood of 
significant adverse transboundary impact arising from a proposed activity, any party can submit a question to an inquiry commission (Art. 3 (7)). Detailed provisions concerning the nature and procedures are provided for in the Convention's Appendix IV. Generally speaking, provisions relating to the submission of a dispute to an external court of tribunal require the agreement of all parties to the dispute whether ad hoc or pursuant to the prior declaration, as provided for in the 1985 Vienna Convention on the Protection of the Ozone Layer. However, a few MEAs provide stronger provisions in relation to such procedures. For instance, the International Convention for the Prevention of Pollution from Ships ([signed 2 November 1973, entered into force 2 October 1983] 1340 UNTS 184; 'MARPOL Convention') provides that in the event of failures to settle the dispute by negotiation, any party can submit the dispute to arbitration in accordance with procedures set out in Protocol II MARPOL Convention; and according to Art. X of that Protocol, the tribunal's award is final and without appeal.

Finally, it has to be stated that settlement of dispute procedures in MEAs have not been used in parallel with non-compliance procedures with the one exception of the Inquiry Commission under the Espoo Convention (see below para. 83).

\section{Non-Compliance Procedures: General OUTLine ${ }^{15}$}

The UNEP Guidelines provide for the setting up of compliance mechanisms in two different situations. The first is the inclusion of such mechanisms in newly negotiated MEAs with a view to assisting parties having compliance problems and addressing individual cases (para. 14 (d)) and the second is the introduction or enhancement of these procedures after an MEA has come into effect, provided such procedures had been authorized by an MEA, subsequent amendment or COPs, as appropriate, and consistent with applicable international law (para. 16).

Non-compliance procedures at the regional level were first initiated in the 1993 Lucerne ECE Ministerial Declaration (Second Ministerial Conference Environment for Europe 'Political Dimension of the Process Environment for Europe: Declaration' [30 April 1993]), which called upon contracting parties to MEAs to adopt non-compliance procedures, which would simplify the process of compliance with environmental obligations, by making such processes transparent, non-confrontational, and friendly. The UNEP Guidelines identify the following objectives and elements in relation to non-compliance procedures ('NCPs'):

a) establishment of a body to centralize considerations of the compliance issues (such bodies are generally referred to as either 'Compliance' or 'Implementation' Committees) and differ as to

\footnotetext{
${ }^{15}$ See in general on non-compliance procedures: T Treves and others (eds), Non-Compliance Procedures and Mechanisms and the Effectiveness of International Environmental Agreements: A Project of Universities of Milan, Bologna and Parma Co-Financed by the Italian Ministry of University and Research (2009).
} 
whether their members are 'party representatives' or elected experts sitting on the basis of their expertise;

b) identification of situations of non-compliance and their causes and formulation of appropriate responses with a view to promoting, facilitating and securing compliance;

c) provision of procedures to secure the above-objectives which may be non-adversarial and which include the safeguards for those involved;

d) provision, also, of a means to clarify the content of a MEA in order to assist in the prevention of dispute.

It is the underlying characteristic of NCPs that they are intended to provide a non-confrontational procedure, the objective of which is to facilitate compliance by Parties in difficulties and to promote the overarching objectives of MEAs. As it has been expressed, NCPs aim at being 'nonconfrontational, transparent, cost-effective and preventive in nature' (Basel Convention on the Control of Transboundary Movements COP 6, Decision $\mathrm{VI} / 12$ 'Establishment of the mechanism of the Implementation and Compliance' para. 2).

\section{The Montreal Protocol non-compliance procedure}

The classical NCP, as it may now be regarded, was introduced under the Montreal Protocol in 1992 by the fourth Meeting of the Parties ('MOP') in Copenhagen on the basis of the enabling clause, contained in Art. 8 Montreal Protocol on Substances that Deplete the Ozone Layer. This NCP has served as a blueprint for other NCPs under MEAs. The majority of NCPs follow this facilitative model, which was first introduced under the Montreal Protocol. However, a new trend was developed by the compliance mechanism under the Kyoto Protocol, the stated objectives of which were: 'to facilitate, promote and enforce compliance with the commitments under the Protocol' (emphasis added). This 'harder' objective led to a structure for the Kyoto Protocol's compliance procedure which is different from the other NCPs (see below paras 82-83). The NCP established a body to address compliance matters which is called the 'Implementation Committee' ('IC') and which consists of 10 parties elected by the MOP based on 'equitable geographical distribution'.

There are three ways to bring the case before the IC:

(1) by a party itself in non-compliance or threatened with noncompliance ('despite having made its best, bona fide efforts, it is unable to comply fully with the obligations under the Protocol' $\left[4^{\text {th }}\right.$ MOP Annex IV para. 4]);

(2) by any other party or parties which have reservations as to the compliance of a party to a Montreal Protocol;

(3) by the Secretariat if it becomes aware of non-compliance during the preparation of its report.

The functions of the IC comprise the following elements:

a) to receive, consider, and report on any submission;

b) to receive, consider, and report on any information or observations forwarded by the Secretariat in connection with the preparation of the 
reports referred to in Art. 12(c) Montreal Protocol and on any other information received and forwarded by the Secretariat concerning compliance with the provisions of the Protocol;

c) to request, where it considers necessary, through the Secretariat, further information on matters under its consideration;

d) to identify the facts and possible causes relating to individual cases of noncompliance referred to the Committee, as best it can, and make appropriate recommendations to the Meeting of the Parties;

e) to undertake, upon the invitation of the party concerned, information-gathering in the territory of that party for fulfilling the functions of the Committee;

f) to maintain, in particular for the purposes of drawing up its recommendations, an exchange of information with the Executive Committee of the Multilateral Fund related to the provision of financial and technical co-operation, including the transfer of technologies to parties operating under Art. 5 (1) Protocol.

The IC submits its report to the MOP, which reviews the information and recommendations to decide the best way 'to bring about full compliance with the Protocol' ( $4^{\text {th }}$ MOP Annex IV para. 9). The IC may assist the MOP in that task, but the MOP is the body charged with making the decision.

Any party whose compliance is under consideration but which is not at the time a member of the IC is entitled to participate in the consideration of its non-compliance by the Committee. On the other hand, no party involved in the matter under consideration by the IC can take part in the elaboration and the adoption of IC's recommendation to the MOP in its case of noncompliance. There are also provisions to protect the confidentiality of information received by the IC in confidence.

\section{Indicative list of measures}

The same meeting of the MOP which adopted the 'Non-Compliance Procedure' ( $4^{\text {th }}$ MOP Annex IV) also adopted the 'Indicative List of Measures that Might be Taken by the Meeting Parties in Respect of Non-Compliance with the Protocol' ( $4^{\text {th }}$ MOP Annex V). These measures, which as their title suggests, were not intended to be exhaustive, include:

(A) Appropriate assistance, including assistance for the collection and reporting of data, technical assistance, technology transfer and financial assistance, information transfer and training.

(B) Issuing cautions.

(C) Suspension, in accordance with the applicable rules of international law concerning the suspension of the operation of a treaty, of specific rights and privileges under the Protocol, whether or not subject to time limits, including those concerned with industrial rationalization, production, consumption, trade, transfer of technology, financial mechanism, and institutional arrangements.

In 1994 the Russian Federation and several other former Communist bloc States made a statement to the MOP (which was treated as constituting a submission under the provisions that are referred to above para. 59 that they might fail to meet their Ozone Depletion Substances ('ODS') phase out obligations under the Protocol, due in part to economic and other domestic 
problems. In response to Russia's impending non-compliance, the IC recommended that measures be taken under paragraph $\mathrm{C}$ of the Indicative List imposing suspension of Russia's right to export to other non-Article 5 parties, or to Article 5 parties, to meet their basic domestic needs. Faced with Russia's forceful objection to this course, inter alia, on the grounds that the provisions of the Indicative List were intended to be applied only incrementally and that the MOP had not first applied the facilitative measures under (A) and (B) of the Indicative List, the MOP reworded the IC's draft decision to state positively that Russia was to be 'allowed' to export to the non-Article 5 parties of the former USSR (which traditionally depended on Russia for their supply of ODS, leaving the proposed restriction merely to be implied). The MOP also left in place conditions concerning in particular reporting and provision of plans to achieve compliance under the Protocol which Russia had to meet if it was to obtain the financial assistance which it sought. Russia continued to protest against this decision but, while nothing further was said about the implied trade restriction, it appears that by 1996 Russia had started to act in accordance with it. Thereafter, the IC continued to monitor Russia's performance and, in light of its efforts to meet the conditions imposed, began to authorize the provision to it of financial assistance. Eventually, at its $15^{\text {th }}$ Meeting in 2003, the MOP recognized with appreciation the return to compliance of Russia. There were certain problems with the implementation of the obligations under the Montreal Protocol by developing countries. For example, concerning China there were potential challenges identified regarding implementation, e.g. many of the Chinese enterprises that produce and consume ODS are spread out and therefore it is difficult to change the production system. Another problem is the complexity of the bureaucracy and the difficulty of negotiating with Chinese officials. China's percentage of the world total ODS had increased significantly from 3\% in 1986 to $10 \%$ in 1994. It is presumed that some industries will resist the attempts to reduce ODS. China noted the lack of sufficient funding (as well as the complicated procedures to obtain funding from the Multilateral Fund) and the lack of development concerning the technology transfer from developed to developing countries ${ }^{16}$. In India similar concerns were voiced, in particular the lack of mandatory technology transfer and the very high costs of the elimination of ODS and lack of funds ${ }^{17}$. Brazil appears to be successful in dealing with the challenges arising from the implementation of targets set under the Montreal Protocol. The reasons were the transparency in the implementation, the involvement of all actors, and a high level of NGO pressure exerted upon reluctant representatives of industries ${ }^{18}$. In Cameroon, the problems of the implementation of the Montreal Protocol related to the political and social situation in the country. It was also suggested that the general laxity in the provisions of the Protocol regarding developing countries

\footnotetext{
${ }^{16}$ See, in general, M Oksenberg, E Economy 'Introduction: China Joins the World' in E Economy, M Oksenberg (ed), China Joins the World: Progress and Prospects (1999) 1.

${ }^{17}$ RJ Herring, E Bharucha 'India: Embedded Capacities' in E Brown-Weiss, HK Jacobson (eds) Engaging Countries: Strengthening Compliance with International Environmental Accords (1998) 395.

${ }^{18} \mathrm{M}$ de Aragão, S Bunker 'Brazil: Regional Inequalities and Ecological Diversity in a Federal System' in E Brown-Weiss, HK Jacobson (eds) (n 16) 475.
} 
played a certain role in the lack of efficient implementation ${ }^{19}$. In Hungary implementation is adversely affected by the overly bureaucratic process and financial concerns ${ }^{20}$.

The Protocol does not include any specific provision for reviewing the effectiveness of the compliance mechanism. However, after many years of functioning, certain conclusions were drawn by the parties to the Montreal Protocol as to the effectiveness of the compliance procedure. In particular, it was concluded that the most frequent reason for non-compliance was the need for capacity-building. Furthermore, it became obvious that punitive measures, such as the suspension of rights, were not as effective as assistance and warning. These conclusions are illustrative in the non-compliance history of the Russian Federation.

\section{Examples of other non-compliance procedures}

There are many examples of other non-compliance procedures based on the Montreal Protocol procedures. Almost all global and many regional MEAs now contain NCPs. To mention a few: Mechanism for Promoting Implementation and Compliance with the 1989 Basel Convention; the Compliance Procedures and Mechanisms of the 1996 Protocol to the 1972 Convention on the Prevention of Marine Pollution by Dumping of Wastes and Other Matter; Procedures and Mechanisms under the Kyoto Protocol; Procedures and Mechanisms on Compliance under the 2000 Cartagena Protocol on Biosafety to the 1992 Convention on Biological Diversity; the United Nations Economic Commission for Europe Procedures and Mechanisms for Review of Compliance under the Espoo Convention. Additionally, a number of other MEAs have NCPs in draft, awaiting the final adoption by their COPs/MOPs: draft procedures and mechanisms on compliance with the Rotterdam Convention on Prior Informed Procedure for Certain Hazardous Chemicals and Pesticides in International Trade and the draft non-compliance procedure under the Stockholm Convention on Persistent Organic Pollutants (draft text contained in Annex to Decision SC3/20), Convention on Access to Information, Public Participation in DecisionMaking and Access to Justice in Environmental Matters ("Aarhus Convention'). However, certain procedures exhibit particular features, which are slightly different from the Montreal Protocol model, such as the ones set up under the Kyoto Protocol and the Aarhus Convention.

\section{a) The non-compliance procedure under the 1979 Long-Range Transboundary Air Pollution Convention and its Protocols}

Within the regional context, a procedure set up under the Long-Range Transboundary Air Pollution Convention and its Protocols merits attention. The non-compliance procedure was first established under the Protocol to the ('Second Sulphur Protocol'). The Implementation Committee was established by the Executive Body in 1997 to review compliance by parties with their obligations under the Protocols to the Convention. The

\footnotetext{
19 P Blaikie, J Mope Simo 'Cameroon's Environmental Accords: Signed, Sealed, but Undelivered' in E Brown-Weiss, HK Jacobson (eds) (n 16) 437.

${ }^{20}$ E Comisso and P Hardi with L Bencze 'Hungary: Political Interest, Bureaucratic Will' in E Brown-Weiss, HK Jacobson (eds) (n 16) 327.
} 
Committee's work focuses on three main areas: it reviews periodically compliance with parties' reporting obligations; considers any submission or referral of possible non-compliance by an individual party with any of its obligations under a given protocol; carries out in-depth reviews of specified obligations in an individual protocol at the request of the Executive Body. It has recommendatory functions, although it identified possible measures to be adopted by the parties. The Implementation Committee is not a decisionmaking body. It meets twice a year and reports annually to the Executive Body which makes decisions upon recommendations by the Committee on action to bring about full compliance with the Protocol (including measures to assist the party's compliance). The Implementation Committee consists of eight States Parties. It has the right to assess the information received, which may include information gathering in the territory of the party concerned with its consent. According to Art. 7 para. 2, the parties may decide upon a call for an action to bring about the full compliance with the Protocol, including measures to assist the party's compliance with the Protocol. According to Wolfrum 'this fills the gap left open in the régime of non-compliance of the Montreal Protocol'. ${ }^{21}$

The non-compliance procedure can be triggered by means of submission by the parties or by the Secretariat. The submission may be brought by one or more parties against another party or by a party in respect to itself. Decision 2006/2 'Implementation Committee, its structure and functions and procedures for review ${ }^{22}$ provides that any decision by the Executive Body on measures of implementation or recommendation has to be adopted by consensus.

The Executive Body of the Convention on Long-Range Transboundary Air Pollution has reviewed the non-compliance procedure and supplemented it with another which covers the Convention itself, the Second Sulphur Protocol; and the Protocol Concerning the Control of Emissions of Volatile Organic Compounds or Their Transboundary Fluxes ([adopted 18 November 1991, entered into force 29 September 1997] (1992) 31 ILM 573).

\section{Convention}

b) The non-compliance procedure under the 1998 Aarhus

The Aarhus Convention ([done 25 June 1998, entered into force 30 October 2001] 2161 UNTS 447) grants procedural environmental rights and its fundamental feature is very strong participation of Environmental NonGovernmental Organizations ('ENGOs') (Environment, Role of NonGovernmental Organizations). The NCP was adopted in 2002 in Lucca at the first MOP Meeting. Its NCP has certain features which reflect the character of the Convention. Cases of alleged non-compliance can be brought to the attention of the Compliance Committee (' $\mathrm{CC}$ ') by submissions of parties and referrals by the Secretariat, however they can also be raised by communications from the public (either individuals or groups of individuals, including ENGOs). The members of the $\mathrm{CC}$ are not representatives of the

${ }^{21} \mathrm{R}$ Wolfrum 'Means of Ensuring Compliance with and Enforcement of International Environmental Law' (1998) 272 RdC 9, 120.

${ }^{22}$ UN Doc ECE/EB.AIR/2006/2. 
governments but serving in their personal capacity. Candidates can be nominated for election not only by the parties but also by ENGOs. Under this NCP system, another problem arises regarding the communications from the public, namely whether there is a requirement for the exhaustion of local remedies before the submission of the case before the $\mathrm{CC}$ and whether, if so, local remedies have to be fully exhausted or whether a reasonable level of exhaustion is sufficient. The Parties regularly address issues of compliance, on the basis of the Committee's reports. At the Committee's recommendation, they adopt decisions on general issues of compliance and also decisions on compliance by individual Parties.

The compliance mechanism may be triggered in four ways:

(1) a Party may make a submission about compliance by another Party;

(2) a Party may make a submission concerning its own compliance;

(3) the secretariat may make a referral to the Committee;

(4) members of the public may make communications concerning a Party's compliance with the convention. (NGOs, individuals, group of NGOs and group of individuals).

In addition, the Committee may examine compliance issues on its own initiative and make recommendations; prepare reports on compliance with or implementation of the provisions of the Convention at the request of the Meeting of the Parties; and monitor, assess and facilitate the implementation of and compliance with the reporting requirements under article 10, paragraph 2, of the Convention ${ }^{23}$.

The Aarhus Convention Compliance Committee is a crucial interface between the public and the Parties and underpins the openness and transparency of the Convention.

The Compliance Committee is a unique mechanism built into the Aarhus Convention, ensuring that it is continuously under review and that the Convention's Parties are in compliance with its provisions. Until end of May 2015 more than one hundred twenty communication (cases) had been submitted to the Committee by public. The Committee received two submissions from the Parties (Romania concerning Ukraine and Lithuania concerning Belarus) and no referrals by the secretariat.

\section{c) The non-compliance procedure under the Convention on International Trade in Endangered Species ('CITES')}

The NCP under CITES has developed on the basis of practice which has been elaborated over a long period by resolutions of the COP and the practice of the Standing Committee of the Convention. ${ }^{24}$ This practice was formalized in the 'Guide to CITES Compliance Procedures' by the COP in 2007 (Conference of the Parties of the Convention on International Trade in Endangered Species of Wild Fauna and Flora 'Guide to CITES Compliance Procedures'). ${ }^{25}$ The main organ which decides on matters of compliance is the Standing Committee ('SC') with the COP only giving general policy guidance on compliance issues. The $\mathrm{SC}$ is an executive committee composed

\footnotetext{
${ }^{23}$ http://www.unece.org/env/pp/ccbackground.html.

${ }^{24}$ See on CITES: P Sand 'Whither CITES? The Evolution of a Treaty Regime in the Borderland of Trade and Environment' (1997) 8 EJIL 29-58.

25 3-15 June 2007Conf 14.3.
} 
mainly of regional party representatives from the CITES Management Authorities. It may be called a 'mini COP' which is authorized to adopt decisions on implementation, enforcement, finance, and administration between COP meetings. The legal character of the SC is therefore different from other compliance or implementation committees under MEAs which have a very specific and narrow mandate. By contrast to other compliance procedures, greater emphasis is placed under CITES, which is itself a trade regulating convention, on the use of trade suspension as a means of inducing compliance. Such suspensions, however, when proposed by the SC, are nevertheless voluntary and non-binding. Furthermore, the compliance procedure under CITES has handled far more cases of non-compliance than has been the case under other conventions, some 33 States having been, in 2006 , subject to recommendations to suspend trade. The use of this measure increased in 2000, when it was also applied to infractions in relation to annual reporting and national legislation. However, the efficiency of this measure is not fully explored as no one knows how many parties subject to such recommendations have in fact implemented them as the relevant information is not always included in national reports. States complain from time to time of the economic cost exacted as a result of recommended trade suspensions, and some of them object to it as detrimental to their reputation. However, it has only happened once that a State withdrew from CITES when a trade suspension was recommended, and even then, it later rejoined. It may be concluded that there is a general acceptance by States Parties of the system of trade suspension. The implementation in practice of CITES encounters various difficulties, which can involve understaffing, lack of data and difficulties with enforcement (e.g. Hungary; see Comisso and Hardi). Regarding Russia, it has to be said that efforts had been made in the former Soviet Union to comply with CITES and that the resulting legislation was strict- sometimes stricter than CITES. The situation deteriorated in the late 1980s and 1990s when the government was not able to control trade in CITES species efficiently and certain decisions to boost industry impaired the implementation of CITES. The liberalization of trade also had an impact on the increase of volume of trade in species covered by CITES is one of the most difficult problems to solve is to eliminate poaching, the illegal export of parts of protected species, and flourishing corruption. Similar problems with the implementation of CITES may be observed in China: bureaucracy; the lack of data-sharing; financial mismanagement; and the difficulties in regulating trade in animal products traditionally used in Chinese medicine (Oksenberg and Economy). In India, despite efforts to implement CITES, there are a number of serious obstacles, such as the lack of capacity to check very long borders for illegal trade; insufficient number of enforcement personnel; and corruption (Herring and Bharucha). In Brazil, despite the efforts of the government and the collaboration with neighbouring countries, the implementation of CITES is also problematic due to intense smuggling and the fragility of the country's system of control and the repression of the illegal trade in species protected by CITES (de Aragão and Bunker). Similarly, Cameroon's implementation of CITES is impaired by flourishing poaching, the lack of data and insufficient financial means (Blaikie and Mope Simo). 


\section{d) The non-compliance procedure under the Kyoto Protocol}

A more 'overtly' strong compliance mechanism for the Climate Change regime, the NCP under the Kyoto Protocol differs significantly in its structure and powers from the other compliance procedures. In particular:

a) the NCP has two 'branches': the Facilitative Branch and the Enforcement Branch, the members of which are elected by MOP in their own capacity on the basis of their own expertise rather than as the parties' representatives. This reflects the wording of the objectives of the NCP; b) it is the Compliance Committee itself, rather than the COP/MOP on the recommendation of the Compliance Committee, which, whether in the Committee's Facilitative or Enforcement Branch, takes decisions concerning the consequences of non-compliance;

c) generally, the Facilitative Branch is responsible for providing advice and facilitation to parties in implementing the Protocol and for prompting compliance by the parties. On the other hand the Enforcement Branch is responsible more specifically for determining whether Annex I parties are not in compliance with certain specified provisions of the Protocol, which include their quantified emission limitations or reduction commitments under Art. 3, methodological and reporting requirements under Arts 5 and 7 and, particularly importantly, eligibility requirements for participation in 'flexible mechanisms' under Arts 6, 12, and 17;

d) the Kyoto Protocol Compliance Mechanisms provide different sets of consequences which may be applied, respectively, by the Facilitative and Enforcement Branches. The consequences which may be applied by the Facilitative Branch are basically similar to those applied under other compliance procedures and include eg. provision of advice and facilitation of assistance regarding implementation of the Protocol; facilitation of financial and technical assistance to any party concerned including the technology transfer and capacity building and formulation of recommendations to parties concerned. It should be noted that the reference to parties concerned under the Kyoto Protocol relates to developed States, in contrast to other compliance procedures where it may be equally developing States which are involved.

The most important forms of non-compliance with which the Enforcement Branch is concerned pursuant to its mandate are those relating to parties' emission limitation or reduction commitment under Art. 3, and the eligibility requirements for the flexibility mechanisms. In both cases the Enforcement Branch first makes the determination of non-compliance. Thereafter, the Kyoto Protocol Compliance Mechanism provides different consequences which may be applied in each of these cases, which are closely related to the nature of acts of non-compliance concerned. In instances when a party is found to have exceeded its assigned amount through failure to meet its emission limitation commitment under Art. 3, the Enforcement Branch shall apply a deduction from the parties assigned amount for the second commitment period of 1.3 times the amount of its excess.

It will also apply a suspension of the eligibility of participation in emissions trading under Art. 17 Protocol and will require development of a 'compliance action plan'. In cases of failure to meet the eligibility requirements for Arts 
12 and 17, the Enforcement Branch suspends the eligibility of that party under those articles. It should be noted that these provisions, in particular the 1.3 times reduction in assigned amount for the second commitment period, are of a far more punitive nature than the measures or consequences available under other compliance procedures. It is still too early to evaluate the system of compliance under the Kyoto Protocol, since it was formally adopted under COP/MOP1 in December 2005. However, there is one case of noncompliance by Greece which was decided by the Enforcement Branch in April 2008. Greece was found to be in non-compliance with national systems requirements for countries in 2012 targets. Consequences applied by the Enforcement Branch were that Greece was declared to be in non-compliance, required to submit plan to address its non-compliance, and not eligible to participate in the mechanisms under Arts. 6, 12, and 17.

\section{The relationship between non-compliance procedures and dispute settlement procedures}

Since the establishment of the Montreal Protocol NCP, classical dispute settlement procedures and NCPs coexist in parallel under MEAs. The decision establishing the Montreal Protocol CP provides as follows: The following procedure has been formulated pursuant to Article 8 of the Montreal Protocol. It shall apply without prejudice to the operation of the settlement of disputes procedure laid down in Article 11 of the Vienna Convention.

There are similar provisions in the majority of other NCPs. However, the relationship between these two procedures is still unresolved and has been a subject of controversy. The main issue in relation to these two procedures is that dispute settlement procedure is potentially confrontational and in exceptional cases relies on compulsory third-party settlement (see above), which can be initiated at the request of 'any of the Parties'. The majority of legal settlement of disputes under MEAs depends on the agreement of the parties who must voluntarily submit to the jurisdiction of the court or tribunal concerned. The main concern regarding the existence of the two systems is the possibility of their parallel operation. Therefore, it was suggested that the NCP system must be exhausted first, before the parties could have recourse to dispute settlement procedures. A compliance control regime may be approached as constituting a 'self-contained' regime, thus possibly excluding the settlement of dispute procedures entirely. At present, there is just one example of parallel recourse to the two systems. It concerns a case between Romania and Ukraine under the inquiry procedure of the Espoo Convention as to the construction of a deep water navigational canal. Romania brought a case against Ukraine on the grounds of its breach of the procedure concerning environmental impact assessment, alleging that Ukraine failed to notify Romania that this project may cause adverse transboundary impact and that it failed to ensure effective public participation in the decision-making process. In parallel, under the Aarhus Convention NCP, both Romania and a Ukrainian ENGO sent a communication to the Aarhus Convention Compliance Committee alleging Ukrainian non-compliance with public participation requirements under the Aarhus Convention. The Aarhus Compliance Committee decided that both submissions were admissible. In 
regard to the fact that certain issues were under the determination of the Inquiry Commission under the Espoo Convention, the $\mathrm{CC}$ held that it would not deal with the issues relating to environmental impact in a transboundary context and deferred the discussion on those aspects. The opinion of the inquiry commission rendered in July 2006 was unanimous that proposed works (a deep water navigational canal) were likely to have some significant and adverse transboundary impact, and recommended that a bilateral programme be started as soon as possible due to the fact that certain consequences of the project were inconclusive. In 2006, the Meeting of the COP/MOP of the Aarhus Convention endorsed the 2005 findings of the Inquiry Commission and found that Ukraine breached the provisions on public participation as regards environmental impact assessment.

\section{CONCLUSIONS}

It can be stated that environmental compliance control has developed several original features. It consists of a nexus of States' obligations which vary from in-depth reporting and monitoring to full scale non-compliance procedures. Non-compliance procedures incorporate reporting and monitoring into one sophisticated system which has unique features. Noncompliance procedures are still developing. However, even at this stage of development, they are enriching our understanding of compliance not only in international environmental law, but also in general international law. As evidenced above, environmental compliance control is a very complex issue, which involves many actors and stakeholders at multiple levels and embodies not only activities relating to compliance with a particular MEA but also activities which generally promote compliance with environmental protection standards. Compliance with MEAs should be seen and assessed as a process which, as empirical research suggests, is very much a local matter. The most interesting, from the point of view of international law, are non-compliance procedures. They are in fact the procedures to which States are having recourse in case in non-compliance rather than to settlement of dispute mechanisms. Although there were several cases before the International Court of Justice which concerned environmental matters, the compliance procedures are more suited to decide on non-compliance than settlement of dispute procedures. They are based on a different premise and are mostly nonadversarial, rather to assist than to punish. Their multilateral character also reflects better the global issues concerning the environment. The implementation of the obligations erga omnes partes in the Whaling case was so far an exception. The most fascinating legal issue will be triggering at the same time both the no-compliance mechanism and judicial proceedings. This is the most challenging issue from the point of international law. 


\section{References}

Brown Weiss E, Jacobson HK, 'A Framework for Analysis' in E Brown Weiss and HK Jacobson (eds) Engaging Countries: Strengthening Compliance with International Environmental Accords (1998).

Brunnée J, Toope SJ, 'Environmental Security and Freshwater Resources: Ecosystem Regime Building’ (1997) 91 AJIL 26.

Chayes A 'Compliance without Enforcement' (1997) 91 ASIL Proceedings 53. 175.

Chayes A, Handler Chayes A 'On Compliance’ (1993) 47 IntlOrg

Chayes A, Handler Chayes A, The New Sovereignty: Compliance with International Regulatory Agreements (1998).

Downs GW, Rocke DM, Barsoom PN, 'Is the Good News about Compliance Good News about Cooperation?’ (1996) 50 Int1Org 379.

Keohane RO, Nye JS, Power and Interdependence: World Politics in Transition (1977).

Keohane R, Nye J, 'Power and Interdependence Revisited' (1987) 41 IntlOrg 725.

Koh HH, 'Why Do Nations Obey International Law' (1997) 106 YaleLJ 2599.

Sand P, 'Whither CITES? The Evolution of a Treaty Regime in the Borderland of Trade and Environment' (1997) 8 EJIL 29.

Shelton D (ed) Commitment and Compliance: The Role of NonBinding Norms in the International Legal System (2000)

Treves $\mathrm{T}$ and others (eds), Non-Compliance Procedures and Mechanisms and the Effectiveness of International Environmental Agreements: A Project of Universities of Milan, Bologna and Parma CoFinanced by the Italian Ministry of University and Research (2009).

Wolfrum R, 'Means of Ensuring Compliance with and Enforcement of International Environmental Law' (1998) 272 RdC 9. 